\title{
Article
}

Arq Neuropsiquiatr 2011;69(6):896-899

\section{Temporomandibular disorders in patients with craniocervical dystonia}

\author{
André L. Costa', Lidiane S. Campos², \\ Marcondes C. França Jr. 1,2, Anelyssa D'Abreu ${ }^{1,2}$
}

\begin{abstract}
Temporomandibular disorders are a set of musculoskeletal dysfunctions within the masticatory system, with multiple etiologies. Objective: Since craniocervical dystonia can involve the same neuromuscular structure as the temporomandibular joint, we sought to assess the correlation between temporomandibular disorders and craniocervical dystonia. Method: We applied the Research Diagnostic Criteria for Temporomandibular Disorders to 42 patients with craniocervical dystonia, in order to identify orofacial pain and temporomandibular characteristics on the day of botulinum toxin injection. Results: Twenty-two patients (52.3\%) reported temporomandibular joint pain; 24 (57.1\%), joint sounds; 20 (47.6\%), masticatory muscle pain; and 21 (50\%), diminished jaw mobility. The patients with oromandibular dystonia presented temporomandibular disorders more frequently than did patients with other types of craniocervical dystonia $(p<0.001)$. Conclusion: Temporomandibular disorders occur frequently in patients with oromandibular dystonia. Further studies should address the proper treatment of temporomandibular disorders associated with dystonia.
\end{abstract}

Key words: botulinum toxin, cervical dystonia, cranial dystonia, temporomandibular disorders.

\section{Disfunção temporomandibular em pacientes com distonia craniocervical}

\section{Correspondence}

Anelyssa D'Abreu

Department of Neurology / UNICAMP

Rua Tessália Vieira de Camargo 126

Cidade Universitária Zeferino Vaz

13083-970 Campinas SP - Brasil

E-mail: anelyssa@hotmail.com

\section{Conflicts of interest}

The authors report no

conflicts of interest

\section{Support}

FAPESP

Full financial disclosures of all authors for the past year André L. Costa: none; Lidiane S. Campos: travel grant from Boehringer Ingelheim and Roche; Marcondes C. França Jr: travel grant from Ipsen; Anelyssa D'Abreu: travel grant from Boehringer Ingelheim and Roche

\section{RESUMO}

As disfunções temporomandibulares são um conjunto de alterações musculoesqueléticas no sistema mastigatório de etiologia multifatorial. Objetivo: A distonia craniocervical pode envolver as mesmas estruturas neuromusculares da articulação temporomandibular. Nosso objetivo foi avaliar a correlação entre distúrbios temporomandibulares e distonia craniocervical. Método: Aplicamos o Critério Diagnóstico para Pesquisa em Disfunção Temporomandibular em 42 pacientes com distonia craniocervical a fim de identificar dor orofacial e características da articulação temporomandibular no dia da injeção de toxina botulínica. Resultados: Vinte e dois pacientes (52,3\%) relataram dor na articulação temporomandibular, enquanto 24 apresentaram sons articulares (57,1\%), 20 dor na musculatura mastigatória $(47,6 \%)$ e redução da mobilidade mandibular foi observada em 21 pacientes (50\%). Os pacientes com distonia oromandibular apresentaram disfunção temporomandibular em maior frequência do que aqueles com outros tipos de distonia craniocervical $(p<0,001)$. Conclusão: A disfunção temporomandibular é frequente em pacientes com distonia oromandibular. Novos estudos devem abordar o tratamento adequado das disfunções temporomandibulares associado à distonia.

Palavras-Chave: toxina botulínica, distonia cervical, distonia cranial, disfunção temporomandibular.
Craniocervical dystonia is defined as a group of neurological disorders characterized by involuntary muscle con- tractions that frequently cause twisting, repetitive movements or abnormal postures affecting the periocular, perioral and
${ }^{1}$ Neuroimaging Laboratory; ${ }^{2}$ Department of Neurology, State University of Campinas (UNICAMP), Campinas SP, Brazil. 
laryngeal musculature, as well as mastication muscles and cervical muscles ${ }^{1}$. Clinically, craniocervical dystonia manifests as isolated blepharospasm, laryngeal dystonia, cervical dystonia (CD), oromandibular dystonia (OD) or any combination of these.

Temporomandibular disorder (TMD) is a collective term embracing a number of clinical problems that involve the masticatory musculature, the temporomandibular joint (TMJ) and associated structures, or both ${ }^{2}$. These disorders are characterized by facial pain in the region of the TMJ and the mastication muscles, limitation or deviation in the mandibular range of motion, or TMJ sounds during jaw movement and function ${ }^{3}$. Their prevalence varies, depending on whether single or combination symptoms are used to establish the diagnosis of $\mathrm{TMD}^{4}$. The prevalence of TMD-associated pain in the American population is $4.6 \%$ (6.3\% for women and 2.8\% for men), with higher prevalences in the non-Hispanic population at younger ages, and increasing prevalence with older age ${ }^{5}$. In Brazil, a validated telephone survey including 1,230 inhabitants found that at least one TMD symptom was reported by $39.2 \%$ of the sample, two symptoms by $17.6 \%$ and three or more symptoms by $9.2 \%^{6}$.

There are a close anatomofunctional relationship between the masticatory system, the cervical region and the TMJ. Although associations between cranial and cervical dystonia and the TMD have not been previously investigated, indirect evidence has suggested that there is an association between the two syndromes? ${ }^{7}$.

The aim of this study was to estimate the prevalence of TMD in patients with craniocervical dystonia.

\section{METHOD}

\section{Study population}

This study was approved by the Internal Review Board of our institution, and all patients signed an informed consent form. Thus, the study was conducted in accordance with the ethical standards laid down in the 1964 Declaration of Helsinki. We included 42 individuals with craniocervical dystonia (26 females) through regular follow-up visits to the Movement Disorders Clinic at the University Hospital at UNICAMP. The patients' mean age was 56.1 years (range: $28-86 ; \mathrm{SD}=16.8$ ) and the mean duration of the disease was 15.1 years (range: 3-49; $\mathrm{SD}=9.4$ ). The patients' diagnoses of dystonia had been established by a movement disorder specialist, and all of them were under treatment with botulinum toxin injections. Five patients presented secondary dystonia (four due to neuroleptics and one due to encephalitis), and all the others had primary dystonia. We did not include any patients with isolated blepharospasm or isolated laryngeal dystonia in this evaluation. The patients' diagnoses and dystonia location are presented in Table.

\section{Clinical evaluation}

All the patients underwent a standardized protocol (The Research Diagnostic Criteria for TMD, RDC/TMD, Axis I) ${ }^{8}$, applied by a trained dentist who was a specialist in TMD. The protocol consisted of an interview and systematic evaluation of mandibular range of motion, joint sounds, joint and muscle pain on palpation, and pain on unassisted and assisted mandibular opening.

To calculate the patients' mandibular range of mo-

Table. Classification of the dystonia findings according to etiology and location.

\begin{tabular}{llcc}
\hline Etiology & Location & Absolute number & $\%$ \\
\hline Primary & Cervical & 16 & 38.05 \\
& Cervical/blepharospasm & 1 & 2.4 \\
& Cervical/upper arm & 1 & 2.4 \\
Oromandibular & 3 & 7.15 \\
& Oromandibular/cervical & 3 & 7.15 \\
& Oromandibular/blepharospasm & 16.6 \\
Oromandibular/cervical/blepharospasm & 7 & 7.15 \\
& Generalized (with oromandibular involvement) & 3.15 \\
& Total & 3 & 88.05 \\
& Cervical & 37 & 7.15 \\
Cervical/upper arm & & 2.4 \\
Generalized (with oromandibular involvement) & 3 & 2.4 \\
Total & 1 & 11.95 \\
\hline
\end{tabular}


tion, we measured the maximum opening from a central maxillary incisor to the opposing mandibular incisor. We then measured lateral movements relative to the maxillary midline with the teeth slightly separated. Jaw mobility was rated as normal when the maximum interincisal opening was $\geq 40 \mathrm{~mm}$ and the maximum laterotrusive movement was $\geq 7 \mathrm{~mm}$. When at least one of these measurements was lower than the normal values, it was defined as impaired.

We evaluated patients' TMJ pain on palpation through bilateral manual palpation of the lateral aspect of the condyle. TMJ pain during unassisted mandibular opening was assessed by asking patients to perform maximum voluntary jaw opening. We performed assisted mandibular opening by applying force to each patient's lower and upper incisors with the middle fingers and thumbs. Muscle pain was assessed by bilateral manual palpation of the anterior, posterior and middle temporalis muscle; the tendon of temporalis; the superficial and deep masseters; the lateral pterygoid muscle; the anterior and posterior digastric muscles; and the cervical muscles.

We evaluated bruxism by means of a standardized interview. The patients were asked about grinding or clenching of the teeth, and they were examined intraorally to revealed any incisal and/or occlusal wear on the teeth.

We did not address secondary dental problems caused by TMD, in this evaluation. The patients were evaluated on the day scheduled for botulinum toxin application, prior to injection.

\section{Statistical analysis}

We used the Systat 9.0 for Windows software package (SPSS, Inc., Chicago, Illinois, USA). We calculated the mean, range and standard deviation to describe continuous variables. Comparisons between groups were done by means of the t-test and Fisher's exact test. The significance level was established at $\mathrm{p}<0.05$.

\section{RESULTS}

Twenty-two patients (52.3\%) reported TMJ pain, while $24(57.1 \%)$ had joint sounds, $20(47.6 \%)$ reported masticatory muscle pain and 21 (50\%) presented diminished jaw mobility. The TMD diagnosis based on RDC/ TMD was: disc displacement $(n=23)$, myofacial pain $(n=20)$, arthralgia $(n=23)$ and arthrosis $(n=1)$.

We performed a secondary analysis in which we divided the patients into two different groups: patients with oromandibular dystonia (OD) $(n=20)$, and those without oromandibular dystonia (NOD) $(n=22)$. There were no significant differences in age $(\mathrm{p}=0.35)$, disease duration $(\mathrm{p}=0.37)$ or gender distribution $(\mathrm{p}=0.23)$.

We diagnosed TMD in all OD patients and in three
NOD patients. We also found bruxism in eight OD patients and two NOD patients. The mean mouth opening was $42 \mathrm{~mm}$ for NOD and $39 \mathrm{~mm}$ for OD ( $\mathrm{p}=0.4)$. However, taking $40 \mathrm{~mm}$ to be the normal magnitude for maximum mouth opening, only six OD patients had a normal mouth opening. Three OD patients had a permanent jaw opening.

We found a statistically significant difference between the two groups regarding the frequency of TMJ pain. Seventeen OD patients suffered TMJ pain, while only five patients in the NOD groups reported TMJ pain $(p<0.001)$. We also found similar differences in all other variables studied: presence of joint sounds $(\mathrm{p}<0.001)$, pain on palpation of the masticatory muscles $(\mathrm{p}<0.001)$, restriction of movement $(\mathrm{p}<0.001)$ and disc displacement $(\mathrm{p}<0.001)$. For further details see Figure.

\section{DISCUSSION}

To our knowledge, this is the first comprehensive clinical study on temporomandibular disorders in patients with craniocervical dystonia. We found a very high prevalence of TMD in patients with craniocervical dystonia, especially in those with OD.

The joint disc of the TMJ is vulnerable to injury because of its limited ability to redistribute the pressure and stress within the joint. This makes the TMJ highly susceptible to overload damage 9 . OD is probably an important precipitating factor in the development of the hypertrophic responses in the subchondral bone and disc that eventually alter the articular space. Disc displacement is believed to result from trauma, due to impact or hyperextension of the joint ${ }^{10}$. Conversely, OD can originate from dysfunction at the central and peripheral levels of the motor system, and disruption of the sensory pathway at the level of the basal ganglia has been implicated ${ }^{11}$.

Primary pain in one of the structures of the stomatognathic system may also lead to secondary changes at

\section{Patients with TMD symptoms/signs according to group}

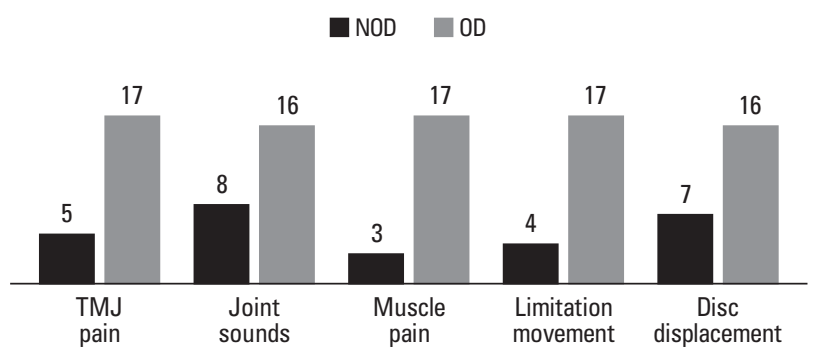

NOD: no oromandibular dystonia; OD: oromandibular dystonia; TMD: temporomandibular disorders.

Figure. Absolute number of patients with TMD symptoms and signs according to group. 
distant sites and this may turn into a vicious cycle that perpetuates pain $^{12}$. TMD signs and symptoms were not as frequent in $C D$ subjects. Although some studies have suggested that there may be an association between head and cervical pain and $\mathrm{TMD}^{13}$, our results do not corroborate such findings.

The treatment for craniocervical dystonia relies mainly on botulinum toxin injections ${ }^{14}$. Interestingly, some authors have also suggested that botulinum toxin injections should be used to treat $\mathrm{TMD}^{15}$. Therefore, further studies should now address the impact of regular botulinum toxin injections on OD-associated TMD, including TMJ and masticatory muscle pain, joint sounds, disc displacement and movement limitation. When only partial improvement in TMD is achieved, evaluation and treatment by a TMD specialist may provide additional benefit.

ACKNOWLEDGEMENTS - The authors are grateful to Dr. Joseph Friedman for reviewing this manuscript.

\section{REFERENCES}

1. Colosimo C, Suppa A, Fabbrini G, Bologna M, Berardelli A. Craniocervical dystonia: clinical and pathophysiological features. Eur J Neurol 2010;17 (Suppl 1):S15-S21.

2. Truelove EL, Sommers EE, LeResche L, Dworkin SF, Von KM. Clinical diagnostic criteria for TMD. New classification permits multiple diagnoses. J Am Dent Assoc 1992;123:47-54.
3. Costa AL, D'Abreu A, Cendes F. Temporomandibular joint internal derangement: association with headache, joint effusion, bruxism, and joint pain. J Contemp Dent Pract 2008;9:9-16.

4. Poveda RR, Bagan JV, Diaz Fernandez JM, Hernandez BS, Jimenez SY. Review of temporomandibular joint pathology. Part I: classification, epidemiology and risk factors. Med Oral Patol Oral Cir Bucal 2007;12:E292-E298.

5. Isong U, Gansky SA, Plesh O. Temporomandibular joint and muscle disorder-type pain in U.S. adults: the National Health Interview Survey. J Orofac Pain 2008;22:317-322.

6. Goncalves DA, Dal Fabbro AL, Campos JA, Bigal ME, Speciali JG. Symptoms of temporomandibular disorders in the population: an epidemiological study. J Orofac Pain 2010;24:270-278.

7. Wiesinger B, Malker $\mathrm{H}$, Englund E, Wanman A. Does a dose-response relation exist between spinal pain and temporomandibular disorders? BMC Musculoskelet Disord 2009;10:28.

8. Dworkin SF, LeResche L. Research diagnostic criteria for temporomandibular disorders: review, criteria, examinations and specifications, critique. $J$ Craniomandib Disord 1992:6:301-355.

9. Cairns BE. Pathophysiology of TMD pain--basic mechanisms and their implications for pharmacotherapy. J Oral Rehabil 2010;37:391-410.

10. Gallo LM. Modeling of temporomandibular joint function using MRI and jaw-tracking technologies--mechanics. Cells Tissues Organs 2005;180: 54-68.

11. Fabbrini G, Defazio G, Colosimo C, Thompson PD, Berardelli A. Cranial movement disorders: clinical features, pathophysiology, differential diagnosis and treatment. Nat Clin Pract Neurol 2009;5:93-105.

12. Sessle BJ, Hu JW. Mechanisms of pain arising from articular tissues. Can J Physiol Pharmacol 1991;69:617-626.

13. Nicolakis $P$, Nicolakis $M$, Piehslinger $E$, et al. Relationship between craniomandibular disorders and poor posture. Cranio 2000;18:106-112.

14. Tan EK, Jankovic J. Botulinum toxin A in patients with oromandibular dystonia: long-term follow-up. Neurology 1999;53:2102-2107.

15. Jeynes LC, Gauci CA. Evidence for the use of botulinum toxin in the chronic pain setting--a review of the literature. Pain Pract 2008;8:269-276. 